\title{
Feasibility of Cultivating Artemisia afra Jacq. ex Willd in Côte d'Ivoire (Daloa) and Evaluation of Its Genetic Diversity on the Basis of Phenotypic Variations
}

\author{
N'Guessan Olivier Konan ${ }^{1 *} \quad$ Adjoua Jocelyne Andréa Konan ${ }^{1} \quad$ Léonard Kouamé $^{1}$ \\ Doffou Sélastique Akaffou ${ }^{1}$ Guy Mergeai ${ }^{2}$ \\ 1.Laboratory of Crop Improvement, Agroforestry Unit, Jean Lorougnon Guédé University, BP 150 Daloa, Côte \\ d'Ivoire \\ 2.Laboratory of Tropical Agroecology, Gembloux Agro-Bio Tech, Liège University, 2 passage des Déportés, B- \\ 5030 Gembloux, Belgium
}

\begin{abstract}
In the southern African regions, Artemisia afra Jacq. ex Willd is one of the most popular and commonly used herbal medicines. In recent years, $A$. afra has received much attention from the scientific community and its use is being investigated in the modern diseases like diabetes, cardiovascular diseases, cancer, and respiratory diseases. This growth in popularity could pose a threat to the species due to intensive harvesting. Indeed, overexploitation is a growing problem for many medicinal species in Africa. To sustain the production and availability of $A$. afra, cultivation seems to be a good strategy and an alternative to collecting in the wild. Unlike A. annua L. (source of artemisinin), little information is available on the cultivation of $A$. Afra in West African countries. In this study, feasibility of cultivating A. Afra in Côte d'Ivoire was evaluated and the extent of its genetic diversity was assessed based on morphological variations. A. аппиа L. was used as control. The result showed for $A$. afra, 30 and $28.02 \%$ nursery and field mortality respectively, and $27.77 \%$ and $0 \%$ for $A$. аппиа. A. аппиа showed faster growth and development kinetics during the first 90 days after field transplantation. $A$. апnиa was relatively earlier ( 83 days to flowering on average) than A. afra (207.20 days to flowering on average). Contrary to A. annua, A. afra was sterile and did not give viable seeds, which poses a major problem of acclimatization in the environmental conditions of Côte d'Ivoire. Assessment of morphological traits revealed significant variations within and between species. Multivariate analysis showed important intra and interspecific genetic diversity. The plants of $A$. afra and A. аппиа were grouped separately and six major clusters were found: two clusters in $A$. аппиа (cluster I and II) and four clusters in A. afra (cluster III, IV, V and VI). These results show that further studies need to be considered to make cultivation of $A$. afra possible in Côte d'Ivoire with superior and genetically stable genotypes.
\end{abstract}

Keywords: Artemisia afra, Artemisia annua, genetic diversity, cultivation

DOI: $10.7176 / \mathrm{JBAH} / 10-24-04$

Publication date: December $31^{\text {st }} 2020$

\section{Introduction}

The genus Artemisia belongs to the family Compositae (Asteracea) which is one of the most important family of plants in the world (more than 23000 species from about 1300 genera) (Bremer 1994). This genus consists of about 500 species, occurring throughout the world. Some very important drug leads have been discovered from this genus, notably artemisinin, the well known anti-malarial drug isolated in the past 36 years from the Chinese herb Artemisia annua L. (sweet wormwood) (Liu et al. 2009). More recently, in the past decade, new medicinal benefits were reported for another species of Artemisia, viz. A. afra Jacq. ex Willd with potential benefits to human health. A. afra, commonly known as the African wormwood, is an herb widely distributed in the southern parts of Africa (especially South Africa), where it is one of the important and most widely used herbs in the traditional medicine (Patil et al. 2012). It is used for a variety of ailments like fever, gastro intestinal disorders, respiratory tract related problems, skin afflictions, gynecological problems, malaria (Koehorst et al. 2010, Sunmonu \& Afolayan 2012, Kena \& Lepheana 2016). Different parts of this plant (roots, stems and leaves) are used in many different ways and taken as enemas, poultices, infusions, body washes, lotions, smoked, snuffed or drunk as a tea (Koehorst et al. 2010).

In recent years, $A$. afra has received much attention of the scientific community and pharmaceutical industries and several studies have been carried out so as to verify or support the traditional use of this herb. Thus, many chemical compounds ( $\alpha$-thujone, $\beta$-thujone, artemisyl acetate, artemisia ketone etc.) and several activities (antibacterial, anti-tuberculotic, anti-spasmolytic, anti-histaminic, anti-oxidant, narcotic, analgesic, anti-malarial etc.) were reported (Koehorst et al. 2010, Patil et al. 2012, Kena \& Lepheana 2016). Moreover, the use of this plant is also being investigated in the modern diseases like diabetes, cardiovascular diseases, cancer, respiratory diseases etc.; and even utility patents have been given in United States and in Europe for the use of $A$. afra in diabetes, cancer, diabetes and cardiovascular disease (Patil et al. 2012).

A. afra could be a promising source for the development of novel strategies to cure fatal maladies and there 
is international interest in its chemical properties. However, this dramatic growth in popularity of this herb, the reliance and extensive demands of pharmaceutical industries, and other anthropogenic activities can pose a threat to the species. Indeed, when the effectiveness of a medicinal plant is more widely acknowledged and accepted, over harvesting can result. Overexploitation is a growing problem for many medicinal species in Africa. Hence, serious measures should be taken to sustain the production and availability of $A$. afra, and cultivation is a good strategy and an alternative to collection in the wild. It can be a solution to not only meet increased demand for medicinal plants, but also a tool for biodiversity conservation and poverty alleviation.

Unlike $A$. annua which is reported to be cultivated in many West African countries, very little information is available on the cultivation of A. Afra in West Africa (especially in Côte d'Ivoire). Hence, the objective of this study is to assess the feasibility of cultivating A. Afra in Côte d'Ivoire and to evaluate the extent of its genetic diversity based on phenotypic characters.

\section{Materials and methods}

\subsection{Experimental Site}

The work was carried out at the experimental farm of the Crop Improvement Laboratory of Jean Lorougnon Guédé University, located in the town of Daloa in the center-west of Côte d'Ivoire. Daloa is one of the most agricultural regions of Côte d'Ivoire. The area was under humid tropical conditions with $1317 \mathrm{~mm}$ of rainfall per year and relative dense forest vegetation. The soil of the plot was sandy loam texture with good fertility, properly leveled and well drained. The mean temperature and relative humidity during the experiment period ranged from $24^{\circ} \mathrm{C}$ to $29^{\circ} \mathrm{C}$ and 70 to $87 \%$, respectively.

\subsection{Plant Materials}

The plant material used in this study consisted of 280 plants of $A$. Afra obtained from seeds originating in Malawi and supplied by the Laboratory of Tropical Agroecology of Gembloux Agro-Bio Tech (University of Liège, Belgium). Eighteen plants of $A$. annua were used as controls and were obtained from seeds provided by the same Laboratory of Liège University.

\subsection{Nursery and transplantation in field}

The seeds of $A$. afra and $A$. annua are very small (less than a millimeter) (Figure 1a ). For this reason, they were sown by sprinkling them on the surface of growing trays filled with moist soil. These trays were placed in tanks filled with water to ensure the continual humidification of the soil (Figure 1b). Seedlings at the 2- to 4-leaf stage were transplanted into $200 \mathrm{ml}$ pots and placed under shade (Figure 1c). Then, seedlings in pot of 6- to 10-leaf stage were transplanted in rows on the experimental plot, with a row-to-row spacing of $100 \mathrm{~cm}$ and plant-to-plant spacing of $80 \mathrm{~cm}$ (Figure 1de). Seeding depth was $50 \mathrm{~mm}$ below the soil. Transplanting was done in the afternoon, when the weather was cool, in order to limit heat stress to seedlings and promote their good and fast recovery. 

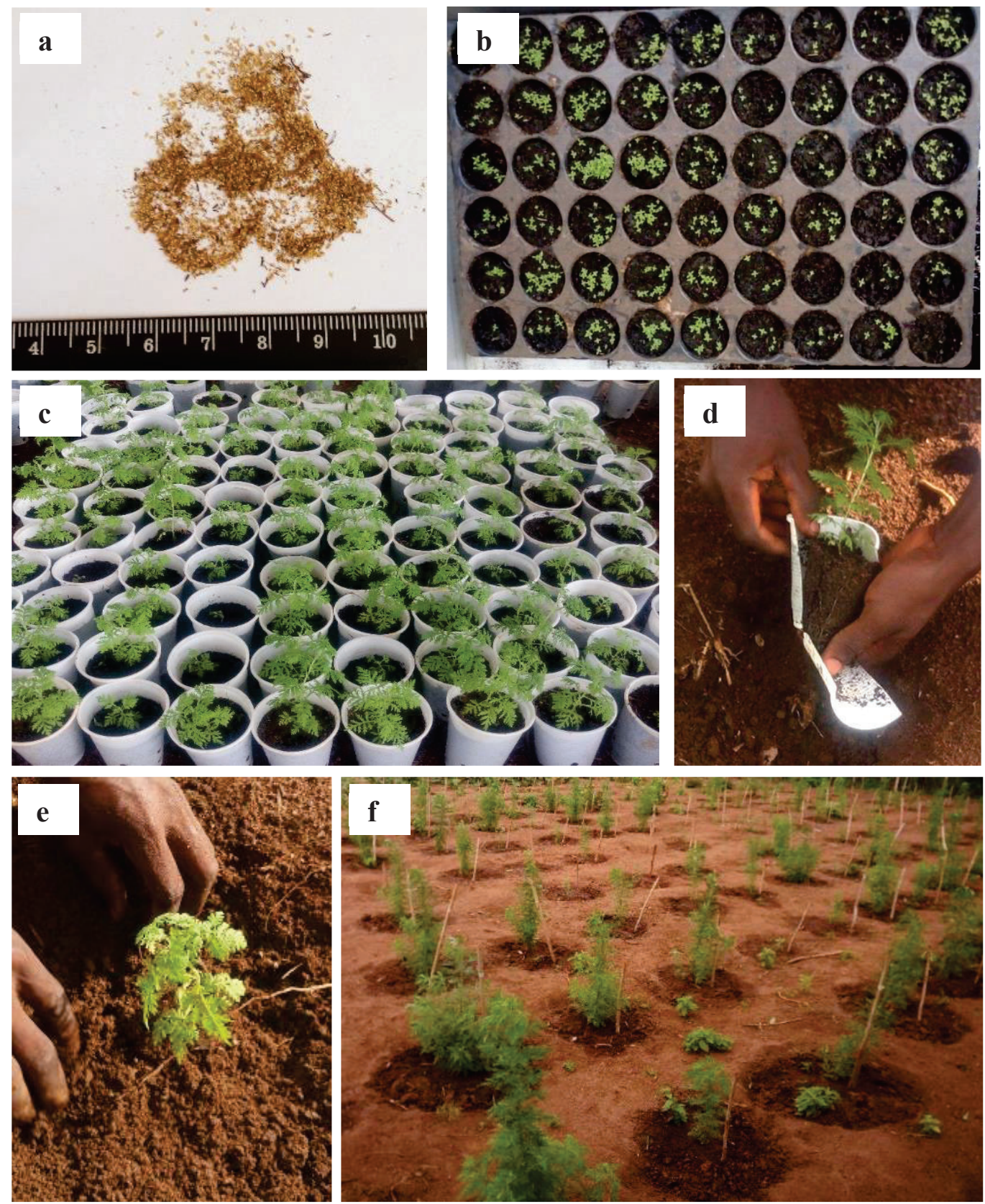

Figue 1. Activities for setting up the nursery and transplanting A. Afra in the field: a) Seeds of A. Afra; b) Growing trays, used for sowing, showing young emerged seedlings of $A$. afra; c) Seedlings of 2- to 4-leaf stage transplanted into $200 \mathrm{ml}$ pots; d, e) Transplanting a seedling into the field; f) Experimental field showing plants of $A$. afra transplanted in the experimental field.

\subsection{Field Managements}

Standard agronomic and management practices were adopted, but no fertilizers and insecticides were applied. Daily watering using a watering can was applied uniformly to all plots when necessary. Manual weeding by hoeing and handpicking were carried out to avoid any competition between the crop and the weeds.

\subsection{Data Collection}

Data collected concerned the mortality rate, the plant fertility, the survival rate after cuttings, and variation in morphological traits:

- Evaluation of mortality rate

The mortality rate was determined by the percentage of dead plants in the nursery and in the field relative to the total number of plants transplanted in pot and in field, respectively. 


\section{- Evaluation of plant fertility}

To have an indication of pollen quality, about 50 pollen grains per plant were analyzed. Flowers were collected in the morning of the day of anthesis (Figure 2a). Pollen grains were dipped in a drop of $1.5 \%$ acetic-carmine solution on a slide for 30 minutes (Figure 2b) and were analyzed under a stereomicroscope (Figure 2c). Only fully stained and large pollen grains were scored as viable and non-aborted (Konan et al. 2020). The quantity of viable pollen was estimated as the percentage of stained pollen.

In addition, the fertility of the plants was evaluated by checking the ability of the seeds, harvested from the studied plants, to germinate after sowing in culture trays.
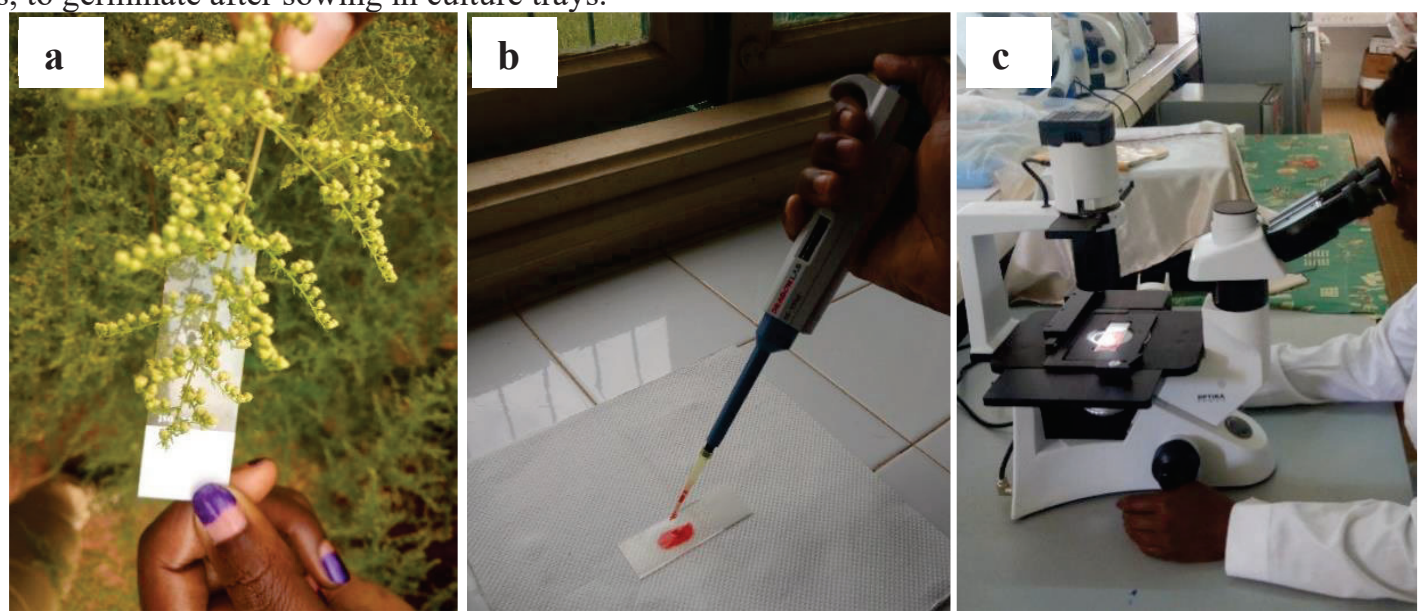

Figure 2. Pollen viability assessment activities: a) Flower and pollen grain collection; b) Addition of an acetic-

carmine solution on pollen grains collected on a slide; c) Examination of the slide under a microscope.

- Survival rate after cuttings

A cuttings test was carried out to assess the possibility of vegetative propagation of the studied Artemisia species. This was carried out on 10 plants of each species. Branches were cut then refreshed at the base leaving 4 leaves at the upper end (Figure 3abc). Each branch was planted in a pot filled with soil (Figure 3d). The number of successful cuttings was then determined and the success rate calculated.
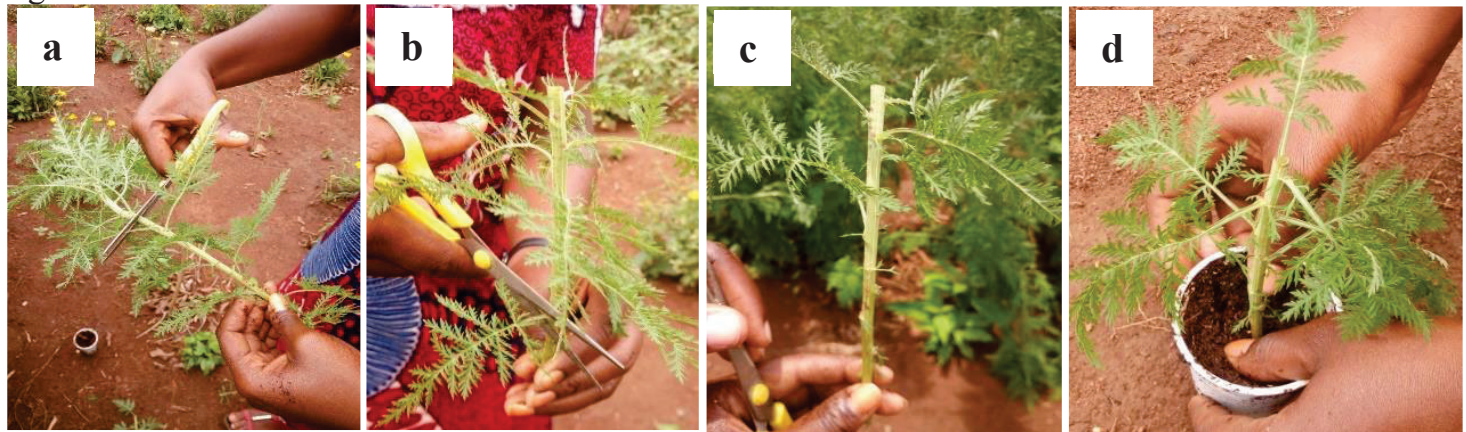

Figure 3. Cuttings of A. Afra: a, b) Preparation of a branch for cuttings; d) A branch ready for cuttings; d)

- Variation in morphological traits

Planting of the prepared branch in a pot filled with soil.

Thirty $\mathrm{A}$. afra plants and $10 \mathrm{~A}$. annua plants were selected at random and used for the assessment of variation in morphological characters. This evaluation concerned 12 phenotypic descriptors which are: Days to emergence (DE), Days to flowering (DF), Number of leaves on the main stem (NL), Number of leaflets (N1), Number of branches connected to the main stem (NB), Plant height at flowering (PH), Stem diameter at base at flowering (SD), Leaf width (LW), Leaf length (LL), Fresh leaf weight (WfL), Dry leaf weight (WdL).

\subsection{Statistical Analysis of Data}

Microsoft Excel Software (2007 edition) was used to compile the data and the software Statistica 7.1 was used for statistical analyses. The means, the standard errors, and variation coefficients were calculated and the data were subjected to Analysis of Variance (ANOVA) to determine the presence of statistically significant differences among the means. A p-value of 0.05 or less was considered statistically significant. The least significant difference (LSD) test was used to separate significantly different means. The morphological variables were also subjected to two methods of multivariate analyses: Principal Component Analysis (PCA) and Cluster Analysis (CA). PCA was done to transform the original variables into a limited number of uncorrelated new variables and to allow the visualization of differences among genotypes, and the identification of groups. The Eigen Values and Eigen 
Vectors were computed, which represent the variance and the loadings of the corresponding principal components (PCs). A biplot analysis was carried out based on the two most important PCs to visualize the pattern of total diversity within the germplasm studied. CA was used to group the genotypes into various clusters according to genetic distance. The clustering was performed using the Euclidian genetic distances. The distance matrix was used to construct a dendrogram based on the Unweighted Pair-group Method with Arithmetic Means (UPGMA). The grouping of the genotypes into clusters based on their genetic relationships was determined and analyzed.

\section{Results}

3.1 Mortality rate in the nursery and in the field

Table 1 presents the results of mortality rates observed in the nursery and in the field. In the nursery, a total of 84 plants out of $280(30 \%)$ and 5 plants out of $18(27.77 \%)$ died respectively in $A$. afra and $A$. annua respectively. In the field, 44 out of 157 plants (28.02) died in A. afra, while 0 out of 13 plants ( $0 \%)$ died in $A$. annua.

Table 1. Results of mortality rates observed in the nursery and in the field for A. afra and A. annua.

\begin{tabular}{llccc}
\hline Species & $\begin{array}{c}\text { Nb of plants } \\
\text { transplanted }\end{array}$ & $\begin{array}{c}\text { Nb of dead } \\
\text { plants }\end{array}$ & $\begin{array}{c}\text { Mortality rate } \\
(\%)\end{array}$ \\
\hline \multirow{2}{*}{ Nursery } & A. annua & 18 & 5 & 27.77 \\
\hline \multirow{2}{*}{ Field } & A. afra & 280 & 84 & 30 \\
\hline & A. annua & 13 & 0 & 0 \\
\hline
\end{tabular}

\subsection{Plant fertility and survival rate after cuttings}

The results of pollen fertility test showed good viable pollen for all the plants of $A$. annua tested. The harvested seeds from the studied plants of this species germinated easily. And even, under the studied plants of $A$. annua, many seedlings were found growing from fallen seeds. On the other hand, all A. afra plants were sterile; and for the germination test of the harvested seeds, no seeds germinated. Under the plants of $A$. Afra, no seedlings growing from fallen seeds were observed.

For the cuttings trial, $90 \%$ survival rate was obtained for $A$. afra, while for $A$. annua $50 \%$ survival rate was found.

\subsection{Growth and development kinetics}

Figure 4 shows the average kinetics of growth, branching and leaf production during 90 days after transplanting the $A$. afra and A. annua plants into the field.

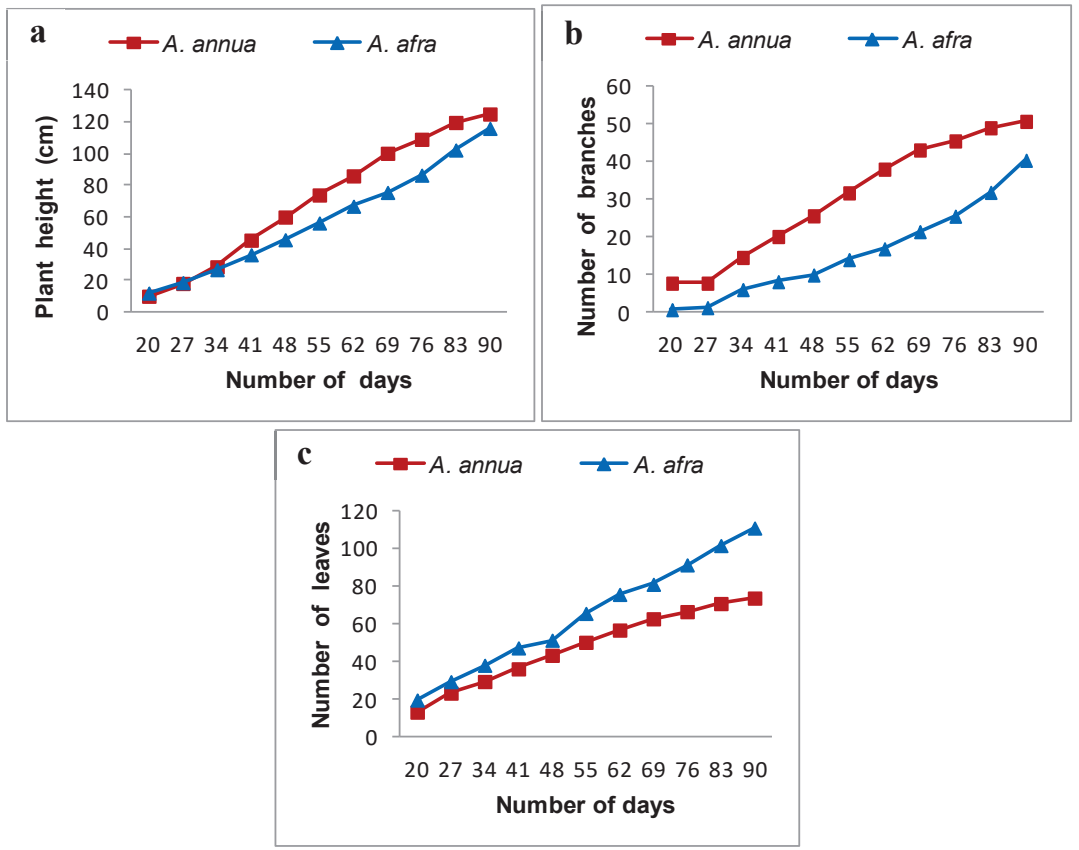

Figure 4. Average kinetics of growth and development during 90 days after transplanting into the field of $A$. afra and $A$. аnnua plants: a) Growth kinetics; b) Branching kinetics; c) Kinetics of leaf production.

The analysis of these kinetics showed differences between the two species. In terms of growth and branching, A. annua grew faster than $A$. afra during the first 90 days after transplanting. In contrast, in terms of leaf production, $A$. afra produced more leaves than $A$. annua during this period. It should be noted that after 90 days $A$. afra exceeded $A$. annua for these three characters. 


\subsection{Variation in morphological traits}

The results of the variation in morphological traits are presented in Table 2. In terms of plant phenology, the days before seedling emergence were on average 4 and 6 for $A$. afra and $A$. annua respectively. The number of days to flowering ranged from 179 to 273 days with an average of 207.20 for $A$. Afra, while it varied from 51 to 111 with an average of 83 for $A$. аnnua. For growth trait, plant height values showed significant variations. Plant height at flowering ranged from 180 to $337 \mathrm{~cm}$ and from 66 to $189 \mathrm{~cm}$ for $A$. afra and A. annua respectively. The values of the plant development parameters also showed variations. Thus, the stem diameter for $A$. afra ranged from 1.9 to $4.9 \mathrm{~cm}$, while for $A$. annua it ranged from 1.5 to $3 \mathrm{~cm}$. The size of the leaves of A. Afra ranged from $8.3 \mathrm{~cm}$ to 14 $\mathrm{cm}$ long with an average of $11.06 \mathrm{~cm}$ and 4.5 to $10 \mathrm{~cm}$ wide with an average of $6.66 \mathrm{~cm}$. For $A$. annua, these values ranged from 2 to $9 \mathrm{~cm}$ long with a mean of 5.96 and 1.5 to $9 \mathrm{~cm}$ wide with a mean of 5.27. A. Afra had a number of leaflets varying from 11 to 23 with a mean of 17.07; while this parameter varied in $A$. annua from 5 to 17 with an average of 12.80. The weight of 20 fresh leaves varied in $A$. afra from 3.08 to $18.28 \mathrm{~g}$ with an average of 8.60 while in $A$. annua it varied from 0.79 to $4.01 \mathrm{~g}$ with an average of 2.65 . For the weight of 20 dry leaves, it varied for $A$. afra from 0.49 to 5.95 with a mean of 2.49 and for $A$. annua from 0.19 to 1.55 with a mean of 0.75 .

Table 2. Variation in morphological traits studied for $A$. afra and $A$. annua plants.

\begin{tabular}{llcccccccc}
\hline Species & & PH $(\mathbf{c m})$ & SD $(\mathbf{c m})$ & DF (day) & LL $(\mathbf{c m})$ & $\mathbf{L W}(\mathbf{c m})$ & NI & WfL (g) & WdL (g) \\
\hline \multirow{6}{*}{ A. afra } & Mean & $235.23^{\mathrm{b}}$ & $3.11^{\mathrm{b}}$ & $207.20^{\mathrm{b}}$ & $11.06^{\mathrm{b}}$ & $6.66^{\mathrm{b}}$ & $17.07^{\mathrm{b}}$ & $8.60^{\mathrm{b}}$ & $2.49^{\mathrm{b}}$ \\
& Min & 180 & 1.9 & 179 & 8.3 & 4.5 & 11 & 3.08 & 0.49 \\
& Max & 337 & 4.9 & 273 & 14 & 10 & 23 & 18.28 & 5.95 \\
& Sd & 34.26 & 0.55 & 24.13 & 1.46 & 1.45 & 2.80 & 3.37 & 1.17 \\
& vc (\%) & 14.56 & 17.51 & 11.64 & 13.24 & 21.79 & 16.42 & 39.21 & 46.94 \\
\hline \multirow{5}{*}{ A. annua } & Mean & $124.85^{\mathrm{a}}$ & $2.38^{\mathrm{a}}$ & $83.00^{\mathrm{a}}$ & $5.96^{\mathrm{a}}$ & $5.27^{\mathrm{a}}$ & $12.80^{\mathrm{a}}$ & $2.65^{\mathrm{a}}$ & $0.75^{\mathrm{a}}$ \\
& Min & 66 & 1.5 & 51 & 2 & 1.5 & 5 & 0.76 & 0.19 \\
& Max & 189 & 3 & 111 & 9 & 9 & 17 & 4.01 & 1.55 \\
& sd & 39.36 & 0.62 & 17.67 & 2.20 & 2.26 & 3.94 & 1.01 & 0.42 \\
& vc (\%) & 31.53 & 25.89 & 21.29 & 36.91 & 42.83 & 30.77 & 38.02 & 56.48 \\
\hline
\end{tabular}

PH: Plant height at flowering; SD: Stem diameter at flowering; DF: Days to flowering; LL: Leaf length; LW: Leaf width; Nl: Number of leaflets; WfL: 20-Fresh leaf weight; WdL: 20-Dry leaf weight. sd: standard error; vc: variation coefficient.

\subsection{Principal Component Analysis (PCA)}

The principal component analysis (PCA) transformed the raw set of data into 8 factors loadings or principal components, with the first principal component (PC1) contributing the most variability $(63.27 \%)$ and the last principal component (PC8) contributing the lowest variability $(0.16 \%)$. Eigen values are often used to determine how many Principal Components to retain. Usually Components with Eigen values less than 1 are excluded. The first two PC (PC1, PC2) had Eigen values greater than 1, and showed therefore high significant variability compared to the rest of the PCs which had Eigen values less than 1. These latter PCs had not been considered as they were not significantly influencing the variability among the genotypes. The percentage of variation explained by the first two PCs, their Eigen value and the factor scores for the traits studied are presented in Table 3 . These two PCs cumulatively explained a variation of $76.80 \%$, including PC1 (63.27\% variation) with a greater weightage on the number of days to flowering, the height of the plants, the number of leaves, the leaf size and the number of leaflets; and PC2 (13.53\% variation) with greater weightage on stem diameter and leaf weight.

Table 3. Principal component analysis of morphological traits in A. afra and A. annua showing Eigen vectors, Eigen values, total and cumulative percentage of variance explained by the first two $\mathrm{PC}$ axes

\begin{tabular}{lcc} 
Trait & PC 1 & PC 2 \\
\hline LL & $\mathbf{- 0 . 4 2}$ & -0.06 \\
LW & $\mathbf{- 0 . 3 2}$ & 0.30 \\
N1 & $\mathbf{- 0 . 3 1}$ & -0.17 \\
WfL & -0.38 & $\mathbf{0 . 4 3}$ \\
WdL & -0.36 & $\mathbf{0 . 4 6}$ \\
DF & $\mathbf{- 0 . 3 7}$ & -0.31 \\
PH & $\mathbf{- 0 . 3 9}$ & -0.21 \\
SD & -0.25 & $\mathbf{- 0 . 5 9}$ \\
\hline Eigen value & 5.06 & 1.08 \\
Total variance (\%) & 63.27 & 13.53 \\
Cumulative variance $(\%)$ & 63.27 & 76.80 \\
\hline
\end{tabular}

PH: Plant height at flowering; SD: Stem diameter at flowering; DF: Days to flowering; LL: Leaf length; LW: Leaf width; Nl: Number of leaflets; WfL: 20-Fresh leaf weight; WdL: 20-Dry leaf weight.

Biplot analysis was carried out based on the first two PCs. Traits and genotypes were shown on the biplots 
(Figure 5 and Figure 6, respectively) to clearly visualize their associations and differences. The scatter plot of the genotypes (Figure 6) showed the pattern of diversity of the species studied. PCA showed a separation between the plants of $A$. afra and those of $A$. апnиa.

\subsection{Cluster Analysis}

A dendrogram (Figure 7) was constructed using the Euclidian distance and based on the Unweighted Pair-group Method with Arithmetic means (UPGMA). This dendrogram showed the relationships between the plants studied and grouped them into 6 major clusters at $58 \%$ level of similarity. ClusterI included 3 plants of $A$. annua, ClusterII 7 plants of $A$. annua, ClusterIII one plant of $A$. afra, ClusterIV 4 plants of $A$. afra, ClusterV 15 plants of $A$. afra and ClusterVI 10 plants of $A$. afra.

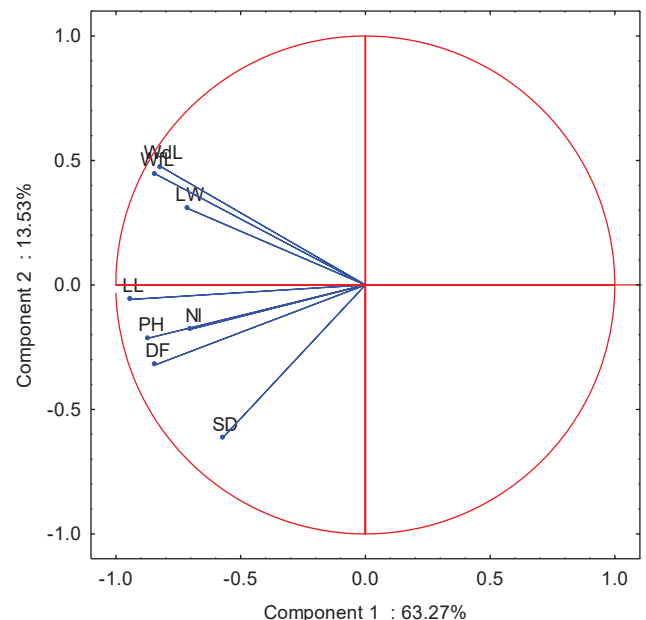

Figure 5. Plot of components weight of the morphological traits studied in A. afra and A. annua.

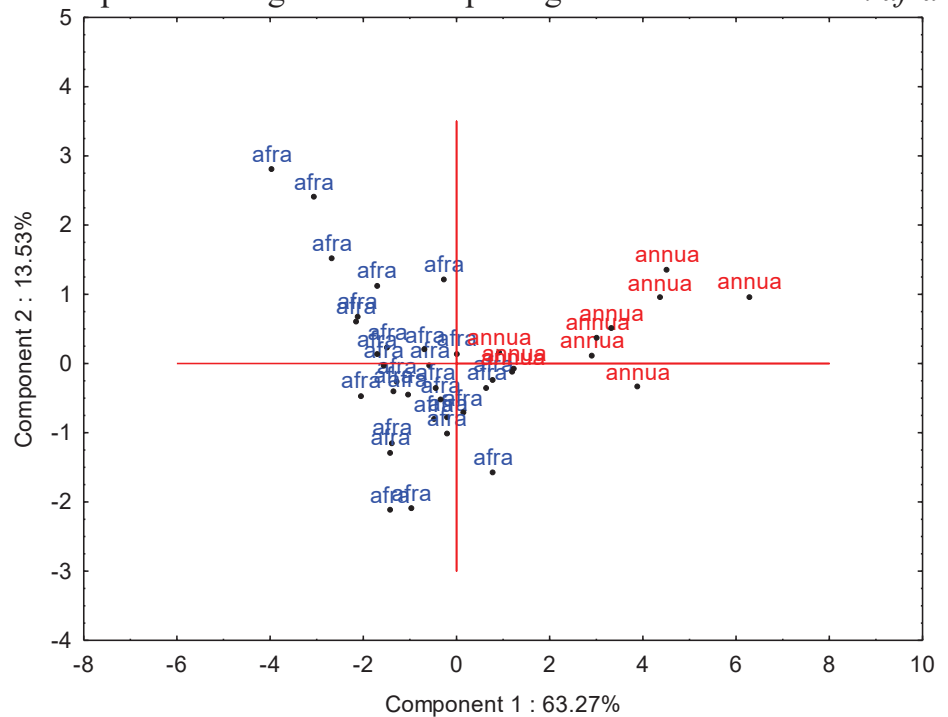

Figure 6. Scatter plot of the first and second principal component analysis for the plant of $A$. afra and A. annua. 


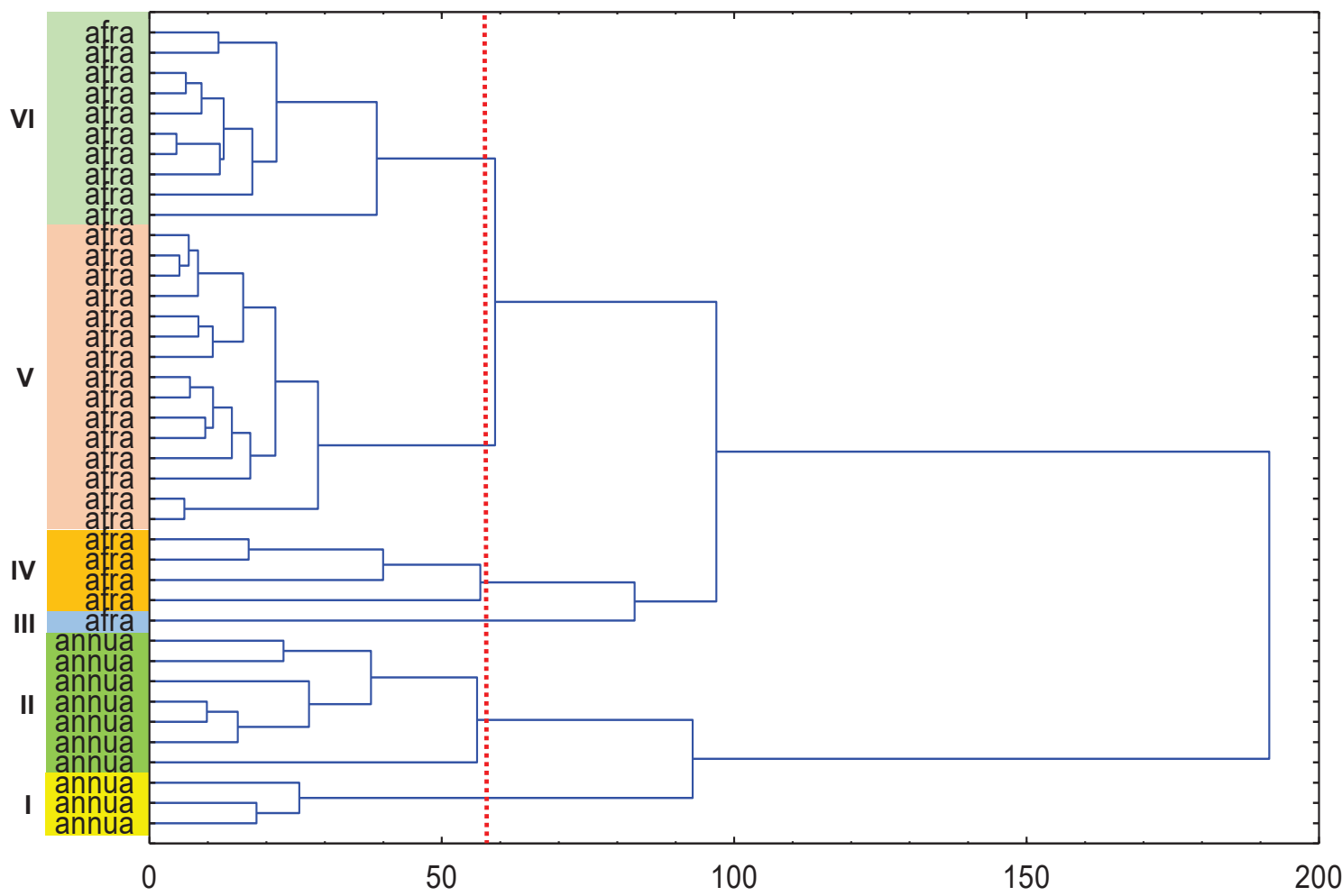

Figure 7. Dendrogram of Euclidian distance illustrating the genetic relationships among the studied plants of $A$. afra and $A$. annua and showing 6 major clusters at 58\% level of similarity.

\section{Discussion}

The natural growth area of $A$. afra is the tropical zone of south-eastern Africa (South Africa, Kenya, Zimbabwe, Malawi, Tanzania, Angola etc.) (Viljoen 2007). The agroecological conditions of this zone are different from those of Côte d'Ivoire (West Africa). Therefore, A. afra must acclimatize to these new environmental conditions. The acclimatization of this species in Côte d'Ivoire will result from its ability to continue to ensure its growth, development, flowering and reproduction under the new conditions. The present study was undertaken to evaluate the level of this acclimatization and also to assess the extent of genetic diversity of the population generated from the seeds received. All the results obtained were compared with those of A. Annua which was used as control because it grows and reproduces well in West Africa as reported by previous studies (Bambara 2007, Onimus et al. 2009, Sounon et al. 2009, Mergeai \& Sankaré 2016).

The seeds of $A$. afra germinated faster than those of $A$. annua (4 and 6 days on average respectively). In addition, the number of seeds of $A$. afra germinated was significantly higher than that of $A$. annua (more than 280 for $A$. afra against 18 for $A$. апnua for the same quantity of seeds sown). This difference in germination time and number of germinated seeds could be explained by a poorer quality of the seeds of $A$. annua received. Indeed, Sounon et al. (2009) obtained germination times for $A$. annua of 3 days in Benin with good germination rate close to the result obtained in the present study. This indicates that $A$. afra and $A$. annua can have the same time and rate of germination.

Nursery and field mortality rates were $27.77 \%$ and $0 \%$ for $A$. annua and $30 \%$ and $28.02 \%$ for $A$. afra, respectively. The mortality rate is higher in $A$. afra than in $A$. annua. This result suggests that $A$. annua would be more vigorous than $A$. afra. However, the mortality rates of these two species did not exceed $30 \%$, indicating an acceptable level of survival. This result is a good indicator of the possibility of acclimatization of these species (Harris, 1989) in Daloa.

The results of the growth kinetics showed a difference between the two species. The growth and branching of $A$. апnиa plants are faster than those of $A$. afra plants during the first 90 days after transplanting in field. This result implies that $A$. afra is relatively late and this is confirmed by the relative great number of days to flowering observed in this species. However, A. Afra quickly produced more leaves than A. annua, which is an interesting trait since leaves are the main part of interest in these species.

The good pollen fertility combined with the good viability of seeds harvested from the plants of $A$. annua testifies to the good reproductive capacity of this species under the environmental conditions of Daloa. Such behavior of A. annua was reported in other countries of west Africa (Bambara 2007, Onimus et al. 2009, Sounon 
et al. 2009, Mergeai \& Sankaré 2016). For A. afra, seeds collected from the plants studied were not viable. This sterility of $A$. Afra in Daloa could probably be due to faulty fertilization. Obviously a problem must make the pollen of $A$. afra non-functional and therefore unfit to fertilize the ovules, hence the sterility observed in the plants of $A$. afra. This result shows a major problem of acclimatization of $A$. afra in the environmental conditions of Daloa. Agroecological conditions in this region did not appear to be favorable for $A$. afra reproduction by seed.

We do not yet know why A. annua is fertile and not $A$. afra. But sterility of plants can be associated with disturbances of tapetal development and degeneration (Papini et al. 1999, Wang et al. 2015). Tapetum is the innermost of the four sporophytic layers of the anther wall that plays an important role in the male fertility of pollen grains. It comes into direct contact with the developing male gametophyte and contains all the nutrients for microspore development and maturation, such as callose, sporopollenin and proteins (Wang et al. 2015). Studies have proven that tapetal tissue has a secretory role, providing nutrients required for microspore and pollen grain development, and defects in tapetal tissue can lead to non-functional pollen (Chiavarin et al. 2000, Wang et al. 2015). Konan et al. (2020) reported that in male sterile plants, pollen grains can be non-functional after their formation because the tapetum in anthers of such plants did not deteriorate and release the food material necessary for the normal development of the pollen grains. There was a possible association of the nonviable character of pollen grains with the nutritive role of tapetum in male sterile plants. Recently, there have been a large number of reports that confirmed this statement (Ma et al. 2015, Wang et al. 2015, Li et al. 2017, Zheng et al. 2019). Perhaps the environmental conditions of Daloa favor such a phenomenon in $A$. afra. Pending more in-depth studies to more understand and resolve this problem of sterility, vegetative reproduction by cuttings appears to be a good means of multiplication of $A$. afra in Daloa. Indeed, cutting tests carried out showed recovery rate of $90 \%$ for this species. $A$. аnnua was also quite suitable for cuttings even if the cuttings success rate were lower than those of $A$. Afra.

Evaluation of morphological traits revealed the existence of significant variation in and between species. This result could be explained by the allogamous reproductive system of these species with a great ease of inter-plant crossing (Mergeai \& Sankaré 2016).

PCA results showed that $76.80 \%$ of the total variability between the plants studied was explained by the first two principal components. This result indicates that a high percentage of the total variance was explained by these two components. PCA showed a distinction between $A$. afra and $A$. annua like the cluster analysis. These results indicate the presence of significant interspecific diversity between these species which implies that $A$. afra and $A$. annua are genetically different with a distinct genetic background. PCA showed that $A$. afra was mainly differentiated from A. аппиа by taller plants, more days to flowering, and larger leaf size with greater number of leaflets; while $A$. апnиa was characterized by a relative precocity, a small height of plants and small leaves in size. The PCA results also revealed a large dispersion of individuals in each species, suggesting the existence of an important intra-specific diversity. With the cluster analysis (CA), this intra-specific diversity was further clarified thanks to a clear clustering by the dendrogram. Two clusters were found in A. annua (cluster I and II) and four clusters in A. afra (cluster III, IV, V and VI). This important inter and intra specific diversity revealed by PCA and $\mathrm{CA}$ are supported by the large phenotypic variation observed in and between these two species. These results suggest that $A$. afra and $A$. аnnua are incipiently domesticated species with mostly xenogamic plants, highly heterozygous for most characteristics, which implies a high degree of segregation.

\section{Conclusion}

At the end of this study, it appears that A. afra can grow and flower in Daloa from seeds coming from its area of origin. However, the plants thus obtained present, unlike those of $A$. annua, a major problem of sterility which therefore prevents the reproduction of this species by seed in Daloa. Multi-site tests should be carried out to validate this result and microscopy studies of flower buds, pollen and seeds should be carried out to more understand this problem of sterility.

Moreover, the multivariate analysis revealed the presence of an important intra-specific diversity both in $A$. afra and in $A$. аппиa. This finding calls for molecular and chemical analysis to assess the extent of this diversity at the molecular and chemical level, which would make it possible to see whether the active principles of interest in these species do not exhibit significant variation in terms of quantity. In this case superior genotype selection should be considered for clonal multiplication by cuttings or other means.

\section{References}

Bambara M. (2007), “Adaptation test of Artemisia annua L. (Asteraceae) to the Sudanese climate: germination, growth monitoring and assessment of biomass and artemisinin concentration", Master thesis, Department of Pharmaceutical Sciences, University of Ouagadougou.

Bremer K. (1994), "In Asteraceae: Cladistics and Classification”, Timber Press, Oregon 752.

Chiavarin A.M., Rosato M., Manzanero S., Jiménez G., González-Sánchez M. \& Puertas M.J. (2000), "Chromosome nondisjunction and instabilities in tapetal cells are affected by B chromosomes in maize", Genetics, 155, 889-897. 
Harris D. R. (1989), “An evolutionary continuum of people-plant interaction”. In: Harris D.R, Hillman GC, editors, Foraging and farming: the evolution of plant exploitation, United Kingdom (London), 11-26.

Kena M.A. \& Lepheana T.F.M. (2016), "Phytotoxic effect of leaf extracts of Artemisia afra and Rhamnusprinoides against some fungal pathogens of Amaranthushybridus", International Journal of Scientific Research and Innovative Technology, 3(1), 51-58.

Koehorst, R., Laubscher, C.P. \& Ndakidemi, P.A. (2010), "Growth response of Artemisia afra Jacq. to different $\mathrm{pH}$ levels in a closed hydroponics system”, Journal of Medicinal Plants Research, 4(16), 1617-1623.

Konan, N.O. \& Mergeai, G. (2020), "Relationship between meiotic behaviour and fertility in backcross-1 derivatives of the $[($ Gossypium hirsutum $\times$ G. thurberi $) 2 \times$ G. longicalyx $]$ trispecies hybrid", Comparative Cytogenetics 14(1):75-95. http://dx.doi.10.3897/CompCytogen.v14i1.47231

Li, D.D., Xue, J.S., Zhu, J. \& Yang, Z.N. (2017), "Gene regulatory network for tapetum development in Arabidopsis thaliana", Frontiers in Plant Science, 8, 1559. https://doi.org/10.3389/fpls.2017.01559.

Liu, N.Q., Van der Kooy, F. \& Verpoorte, R. (2009), “Artemisia afra: A potential flagship for African medicinal plants?”, South African Journal of Botany, 75(2):185-195. DOI: 10.1016/j.sajb.2008.11.001

Ma, Y., Kang, J.,Wu, J., • Zhu, Y. \& Wang, X. (2015), "Identification of tapetum-specific genes by comparing global gene expression of four different male sterile lines in Brassica oleracea", Plant Molecular Biology, 87, 541-554. https://doi.org/10.1007/s11103-015-0287-0.

Mergeai, G. \& Sankaré, K.. (2016), “Artisanal production of powder from A. annua leaves and stems: presentation of the experience acquired at ENSA in Thiès (Senegal)", Moreforless, special edition, $33 \mathrm{p}$.

Onimus, M., Vouillot, J.-M. \& Clerc, G. (2009), “Artemisia herbal tea, artemisia against malaria (ACP)”, [Online] Available: htp:/www.acppaludisme.org/dl/ Artemisinine (5 mars 2020).

Papini, A., Mosti, S. \& Brighigna, L. (1999), "Programmed-cell death events during tapetum development of angiosperms", Protoplasma, 207, 213-221.

Patil, G.V., Dass, S.K. \& Chandra, R. (2012), “Artemisia afra and Modern Diseases", Journal of Pharmacogenomics \& Pharmacoproteomics, 2, 3. DOI: 10.4172/2153-0645.1000105

Sounon, M., Kakaï, G.R., Avakoudjo, J., Assogbadjo, A.E \& Sinsin, B. (2009), "Germination and growth test of Artemisia annua L. on different substrates in Benin", International Journal of Biology, Chemical Science, 3(2), 337-346.

Sunmonu, T.O. \& Afolayan, A.J. (2012), "Evaluation of Polyphenolic Content and Antioxidant Activity of Artemisia afra Jacq. Ex Willd. Aqueous Extract", Pakistan Journal of Nutrition, 11 (7), 520-525.

Viljoen, A. (2007), "Indigenous South African Medicinal Plants Part 2: Artemisia afra (wild wormwood)" South Africa Pharmaceutical Journal, 58.

Wang, S., Zhang, G., Song Q., Zhang, Y., Li, Z., Guo, J., Niu, N., Ma, S. \& Wang, J. (2015), “Abnormal development of tapetum and microspores induced by chemical hybridization agent SQ-1 in Wheat". PLoS One, 10(3), e0119557. https://doi.org/10.1371/journal.pone.0119557.

Zheng, S., Li, J., Ma, L., Wang, H., Zhou, H., Ni, E., Jiang, D., Liu, Z. \& Zhuang, C. (2019), “OsAGO2 controls ROS production and the initiation of tapetal PCD by epigenetically regulating OsHXK1 expression in rice anthers", Proceedings of the National Academy of Sciences of the United States of America, 116, 7549-7558. https://doi.org/10.1073/pnas.1817675116. 